\title{
Corrosion Resistance After Mechanical Deformation of the Ti30Ta Experimental Alloy for Using in Biomedical Applications
}

\author{
Kerolene Barboza da Silva ${ }^{a}$, Reginaldo Toshihiro Konatu ${ }^{a}$, Liliane Lelis de Oliveira ${ }^{a}$, Roberto Zenhei
}

\author{
Nakazato ${ }^{a}$, Ana Paula Rosifini Alves Claro * \\ a Departamento de Engenharia de Materiais, Faculdade de Engenharia de Guaratinguetá, Universidade \\ Estadual Paulista "Júlio de Mesquita Filho" - UNESP, Av. Ariberto Pereira da Cunha, 333, Portal das \\ Colinas, 12.516-410, Guaratinguetá, SP, Brazil.
}

Received: May 18, 2016; Revised: February 4, 2017; Accepted: July 3, 2017

\begin{abstract}
In this study the corrosion resistance of Ti30Ta experimental alloy was evaluated when submitted to different deformation rates. Alloys were processed in arc melting, furnace, forged and treated. The samples were machined in accordance with ASTME9-09 standard to carry out compression tests. The influence of deformation was evaluated by optical microscopy and XRD, and Eletrochemical parameters were analyzed in the most severe condition of deformation (22\%). Corrosion resistance exhibited the same behavior for two conditions, $22 \%$ and without deformation.
\end{abstract}

Keywords: Titanium alloy, Corrosion resistance, Mechanical deformation, Biomaterials

\section{Introduction}

Nowadays, titanium and its alloys are the materials most used for dental implants and in orthopedic implants applications. The Ti-6Al-4V alloy is the most used in biomedical applications, but researches have been showed that aluminum and vanadium could be toxic to the human body and they are associated in the long run with Alzheimer's disease and other degenerative diseases ${ }^{1,2}$.

Thus, new titanium alloys with non toxic elements have been developed ${ }^{3}$. These alloys must exhibit excellent bulk properties, such as low elastic modulus associated to excellent biocompatibility and corrosion resistance. Elements such as niobium $(\mathrm{Nb})$, zirconium $(\mathrm{Zr})$, molybdenum $(\mathrm{Mo})$ and tantalum (Ta) are strong candidates since they allow the reduction of alloy is elastic modulus reaching values closer that of the bone (10-40 GPa $)^{3-10}$. In particular, the Ti-30Ta alloy with $\alpha$ " phase (martensite) has been shown as viable for applications in the manufacture of prostheses due to its excellent corrosion resistance and differentiated combination of low elastic modulus and high mechanical strength ${ }^{5,11,12}$.

The selection of a material to be used in the manufacture of orthopedic implants implies meeting a number of requirements, especially in relation to mechanical strength ${ }^{13}$. The mechanical properties of materials are dependent on their microstructure ${ }^{14}$ obtained through thermal or mechanical treatments ${ }^{13}$ such as deformation, for example. During the plastic deformation the grains undergo changes of the form and orientation increasing the number of dislocations, defects and the area of the grain boundary ${ }^{15}$. The presence of defects promotes microstructural changes and makes the unstable material.

The behavior of $\mathrm{Ti}$ and its alloys during deformation is modified with processing parameters as strain, strain rate and temperature ${ }^{16}$. Given these results, in order to the velop new titanium alloys with better properties and to optimize the conditions of forging process, it is important to understand how such changes in the microstructure caused by deformation interfere in other properties as corrosion resistance. The objective of the study was to investigate the corrosion behavior of Ti-30Ta alloy when cold worked, checking aspects as phase stability and microstructure, for manufacturing prosthesis.

\section{Experimental Procedure}

\subsection{Alloy processing}

Ti30Ta alloy was obtained from the commercial pure metals. Titanium (grade 2) and tantalum (99.9\%). They were melted in a cooper crucible in an arc melting furnace with an inert argon atmosphere and then water cooled. Ingots was melted at least 10 times for a chemical homogenization. Heat treatment was necessary for the homogeneity of the samples at $1000{ }^{\circ} \mathrm{C}$ for $86.4 \mathrm{ks}$ in order to eliminate segregation. The ingots were then cold-worked by a rotary swaging process and solubilized at $950{ }^{\circ} \mathrm{C}$ for $7.2 \mathrm{ks}$ in order to remove residual stress caused by plastic deformation. 


\subsection{Compression tests}

The specimens were machined in accordance with ASTM E9-09 measuring $10 \mathrm{~mm}$ in diameter and $20 \mathrm{~mm}$ in length. To simulate the forging process of the prosthesis, the compression test was carried out in open array where the samples were placed in the center and arrays exerted an axially compressive force, mechanically deforming them by cold compression. The specimen were compressed with the minimum speed provided by the equipment with three different degrees of deformation $(19 \%, 22 \%$ and $44 \%)$ to analyze how the material behaves in relation to the degree of imposed deformation up to the point of its shear (44\%).

\subsection{Microstructural characterization}

\subsubsection{Optical microscopy}

The samples were sectioned in automatic machine with diamond disc (Isomet, Buheler). After the cutting, the grinding was carried out with water using abrasives of silicon carbide (SiC) with a particle size 100 to 2000 . Thereafter, the surfaces were polished with colloidal silica suspension 0.5 $\mu \mathrm{m}$ and oxalic acid $5 \%$, followed by chemical eatching with reagent Kroll by immersion during 15 seconds, washed with running water and dried. The microstructure of the Ti-30Ta alloy was evaluated in an optical microscope (Epiphot 4, Nikkon) using the bright field and polarized light techniques, with varying magnifications.

\subsubsection{X-ray diffraction}

The X-ray diffraction experiments were conducted in a diffractometer (Empyrean, PANalytical). Phases present in the alloy were characterized by $\mathrm{X}$-ray using a $\mathrm{Cu} \mathrm{K} \alpha$ irradiation in the regular range $2 \theta=30-90^{\circ}$ with an accelerating voltage of $40 \mathrm{kV}$ and a current of $30 \mathrm{~mA}$ at a scanning speed of $0.2^{\circ} / \mathrm{sec}$ at room temperature.

\subsection{Corrosion test}

The corrosion resistance of the binary alloy Ti-30Ta was evaluated through eletrochemical tests. One of the samples was manually grinding with sandpaper of granulation 600-1200 mesh until the surfaces were free of risks. The electrochemical cell consisted of three electrodes. The sample of the experimental alloy was used as working electrode, with $1 \mathrm{~cm}^{2}$ exposed area, saturated calomel electrode was used as a reference electrode and a platinum wire as a counter electrode. The eletrochemical measures were realized having as electrolyte a solution of $\mathrm{NaCl} 0.15 \mathrm{M}$ plus $\mathrm{NaF} 0.03 \mathrm{M}$ solution, being the scanned region from $-0.8 \mathrm{~V}$ until values close $3.5 \mathrm{~V}$ with speed $0.166 \mathrm{mV} / \mathrm{s}$. The potentiodynamic polarization curves were obtained with a potentiostat.

\section{Results and Discussion}

Figure 1 shows the micrographs obtained for each one of the analyzed samples with and without deformation and it allows to visualize the changes caused by the compression test and also the existence of $\alpha$ " phase in the alloy in both conditions.

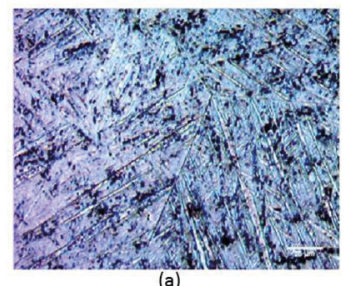

(a)

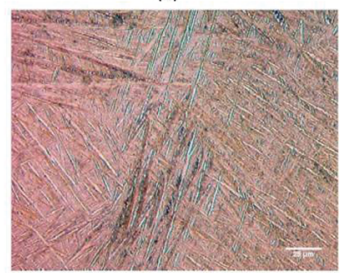

(c)

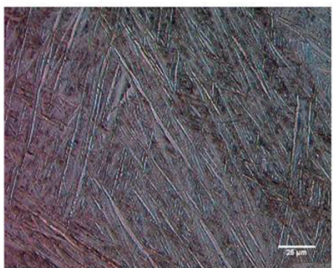

(b)

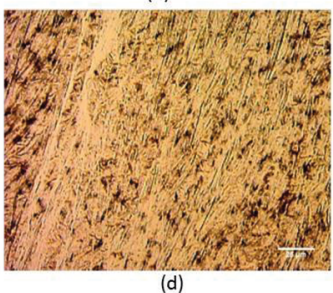

(d)
Figure 1. Optical micrograph of the Ti-30Ta alloy (a) without deformation (b) $19 \%$ of deformation (c) $22 \%$ of deformation (d) $43 \%$ of deformation

The thin and parallel structure (needle-like) shows the formation of the $\alpha$ " phase or martensite. The microstructure of the Ti-30Ta alloy samples in the deformed condition exhibit a higher volume fraction of orthorhombic phase $\alpha$ " (martensite) $)^{17}$, Figure 1 (a) and (b).

In samples with less deformation the refinement of grains occurs however, these don't present a defined orientation, while in the sample with larger deformation the lamellae exhibit a bending at some points and at other points an orientation perpendicular to the compression axis ${ }^{17,18}$. The characterization of the samples by microscopy showed that the $\alpha$ " phase (martensite) trends to align itself with the direction of deformation in samples with deformations close to $20 \%$. For higher deformation was observed the presence of deformation heterogeneities, such as shear bands ${ }^{17}$, Figure 1 (d).

Results of XRD analysis show two types of structures: $\alpha$ " and $\beta$ phases exist in the Ti-Ta alloy studied. The Figure 2 allows to evaluate the results of the material compression.

The formation of $\alpha$ " phase (martensite) in Ti-Ta alloy depends on the composition (Tantalum content) and the quenching rate. When quenched from the $\beta$ field Ti-Ta alloys with tantalum content between 30 and $50 \%$ have $\alpha$ " structure ${ }^{5}$. From analysis of the X-ray spectra it is possible estimate that the cold working process promoted no significant phase changes in its microstructure. 


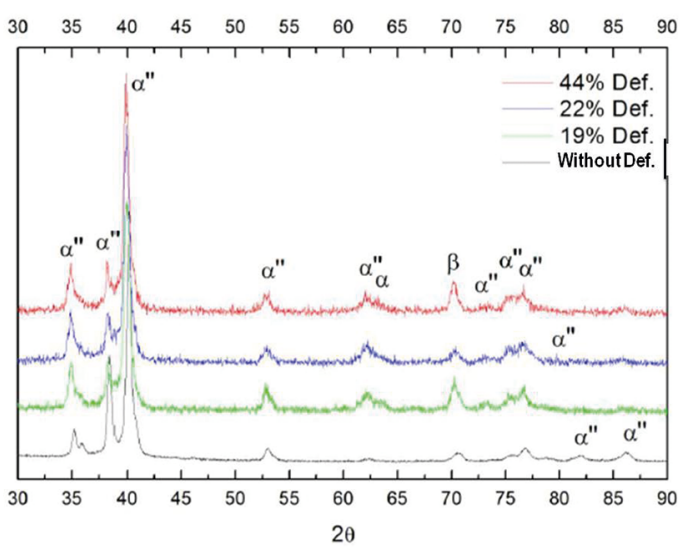

Figure 2. X-ray spectra diffraction obtained for samples analyzed

In the Figure 2 a variation was observed in the intensity of diffraction peaks among samples studied, which can be attributed to the presence of defects. Strains and strain gradients associated with the groups of dislocation are responsible for the increase in the intensity of diffraction. Dislocations and subgrains are types of defect which have important consequences in diffraction. Diffracted intensities from perfect crystals were substantially less than those from deformed crystals, and there is a variation of diffracted intensity with increasing levels of deformation ${ }^{19}$.

The polarization curves for the studied Ti-30Ta alloys is shown in Figure 3. Similar polarization curves were obtained for the samples deformed and without deformation.

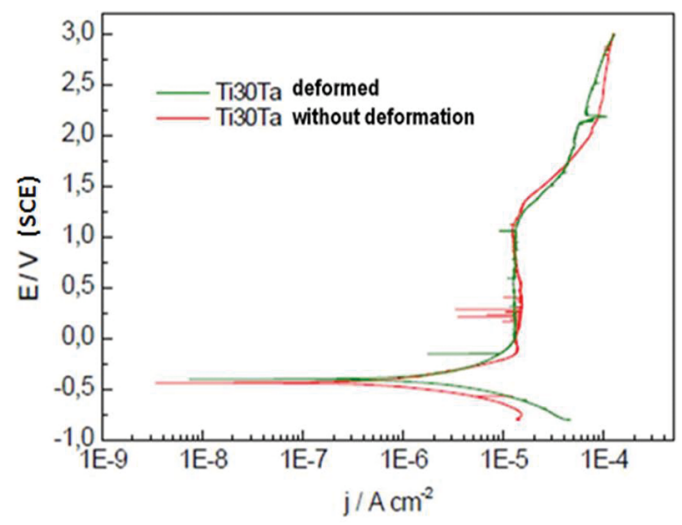

Figure 3. Polarization curves for Ti30Ta alloy in $\mathrm{NaCl} 0.15 \mathrm{M}+$ $\mathrm{NaF} 0.03 \mathrm{M}$ solution

The analysis of some corrosion parameters as passive current density (Ipc), primary passivation potential (Epp) allow the evaluation of the behavior of the alloy studied. The result suggests highly stable passive film on all these samples in $\mathrm{NaCl} 0.15 \mathrm{M}+\mathrm{NaF} 0.03 \mathrm{M}$ solution. When the current density measured by polarization testing is low, the corrosion resistance of an alloy is excellent ${ }^{11,20}$.
From the polarization curves obtained for the Ti-30Ta alloy with and without deformation, Figure 3, it is possible to perceive similar corrosion resistance, since the values of their behavior parameters are very close. The passive current density was around $1.3 \times 10^{-5} \mathrm{~A} / \mathrm{cm}^{2}$ in both conditions indicating formation and growth of a stable oxide on the alloy. The current density in the passive region of Ti30Ta alloy was lower when compared to the other materials used for the manufacture of implants, as pure titanium ${ }^{21,22}$, that it has a passive current density around $1.66 \times 10^{-4} \mathrm{~A} /$ $\mathrm{cm}^{2}$, Figure 4, indicating that the oxide films formed on the surface, $\mathrm{Ta}_{2} \mathrm{O}_{5}$, is more corrosion resistant ${ }^{11,23}$. In Figure 3, it is possible to observe that the start of the dissolution of $\mathrm{Ta}_{2} \mathrm{O}_{5}$ oxide occurs in the potential above $2.5 \mathrm{~V}$ due to the stronger and more stable passive film.

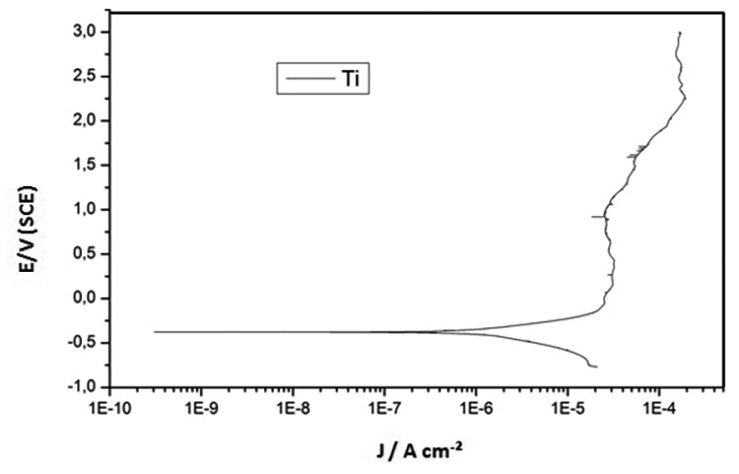

Figure 4. Polarization curves for $\mathrm{Cp} \mathrm{Ti}$ in $\mathrm{NaCl} 0.15 \mathrm{M}+\mathrm{NaF}$ $0.03 \mathrm{M}$ solution

Corrosion behavior of an alloy depends on the environment where it is exposed, temperature and velocity, but it is mainly decided by its chemical composition and the crystal structure has little influence on the corrosion resistance of an alloy ${ }^{11}$.

These results confirmed the negative influence of deformation on the electrochemical behavior of Ti30 Ta alloy deformed and without deformation.

\section{Conclusion}

Using optical microscopy and X-ray diffraction analysis, it was possible to verify the formation among others, of the phase $\alpha$ " or martensitic structure, which in previous studies was shown to have interesting elastic modulus for biomedical applications and by X-ray diffraction was confirmed that there wasn't significant phase change between different levels of deformation studied for Ti30Ta alloy, favoring the possibility of forging of the alloy. Corrosion test showed that the cold forging didn't influence in the corrosion resistance, since there weren't changes in corrosion parameters in both conditions evaluated. 


\section{References}

1. Taddei EB, Henriques VAR, Silva CRM, Cairo CAA. Sinterização a vácuo da liga Ti-35Nb-7Zr-5Ta. Revista Brasileira de Aplicações de Vácuo. 2004;23(2):68-72.

2. Davisdson JA, Mishra AK, Kovacs P, Poggie RA. New surface hardened, low-modules, corrosion resistance, Ti-13Nb-13Zr alloy for total hip arthroplasty. Biomedical Materials and Engineering. 1994;4(3):231-243.

3. Geetha M, Singh AK, Asokamani R, Gogia AK. Ti based biomaterials, the ultimate choice for orthopaedic implants - A review. Progress in Materials Science. 2009;54(3):397-425.

4. Chen Q, Thouas GA. Metallic implant biomaterials. Materials Science and Engineering R. 2015;87:1-57.

5. Zhou YL, Niinomi M, Akahori T. Effects of Ta content on Young's modulus and tensile properties of binary Ti-Ta alloys for biomedical applications. Materials Science and Engineering: A. 2004;371(1-2):283-290.

6. Purcek G, Saray O, Kul O, Karaman I, Yapici GG, Haouaoui M, Maier HJ. Mechanical and wear properties of ultrafine-grained pure Ti produced by multi-pass equal-channel angular extrusion. Materials Science and Engineering: A. 2009;517(1-2):97-104.

7. Kim HM, Miyagi F, Kokubo T, Nakamura T. Effect of heat treatment on apatite-forming ability of Ti metal induced by alkalin treatment. Journal of Materials Science: Materials in Medicine. 1997;8(6):341-347.

8. Niinomi M. Mechanical properties of biomedical titanium alloys. Materials Science and Engineering: A. 1998;243(1-2):231-236.

9. Liu X, Chu PK, Ding C. Surface modification of titanium, titanium alloys, and related materials for biomedical applications. Materials Science and Engineering: R: Reports. 2004;47(34):49-121.

10. Gepreel MAH, Niinomi M. Biocompatibility of Ti-alloys for long-term implantation. Journal of the Mechanical Behavior of Biomedical Materials. 2013;20:407-415.

11. Zhou YL, Niinomi M, Akahori T, Fukui H, Toda H. Corrosion resistance and biocompatibility of Ti-Ta alloys for biomedical applications. Materials Science and Engineering: A. 2005;398(1-2):28-36.
12. Haghighi SE, Lu HB, Jian GY, Cao GH, Habibi D, Zhang LC. Effect of $\alpha$ " martensite on the microstructure and mechanical properties of beta-type Ti-Fe-Ta alloys. Materials \& Design 2015;76:47-54

13. Lopes JFSC. Avaliação de processos de deformação plástica, recristalização e envelhecimento de ligas $\mathrm{Ti}-\mathrm{Nb}$. [Dissertation] Campinas: Universidade Estadual de Campinas, Faculdade de Engenharia Mecânica; 2010. 112 p.

14. Ding R, Guo ZX, Wilson A. Microstructural evolution of a Ti-6Al-4V alloy during thermomechanical processing. Materials Science and Engineering: A. 2002;327(2):233-245.

15. Padilha AF, Siciliano Jr. F. Encruamento, Recristalização, Crescimento de Grão e Textura. São Paulo: ABM, 2005.

16. Lee W, Lin C. High-temperature deformation behaviour of Ti6Al4V alloy evaluated by high strain-rate compression tests. Journal of Materials Processing Technology. 1998;75(1-3):127136.

17. Lopes JFSC, Hayama AOF, Caram R. Comportamento microestrutural da liga $\mathrm{Ti}-30 \mathrm{Nb}$ deformada por laminação a frio. In: VI Congresso Nacional de Engenharia Mecânica; 2010 Aug 18-21; Campina Grande, PB, Brazil.

18. Zhou YL, Niinomi M. Microstructures and mechanical properties of Ti-50 mass\% Ta alloy for biomedical applications. Materials Science and Engineering: A. 2008;466(1-2):535-542.

19. Cullity BD, Stock SR. Elements of X-Ray Diffraction. $3^{\text {rd }}$ ed. London: Pearson; 2010. p. 172-178.

20. Okazaki Y, Rao S, Ito Y, Tateishi T. Corrosion resistance, mechanical properties, corrosion fatigue strength and cytocompatibility of new Ti alloys without Al and V. Biomaterials. 1998;19(13):1197. 1215.

21. Mareci D, Chelaju R, Gordin DM, Ungureanu G, Gloriant T. Comparative corrosion study of Ti-Ta alloy for dental applications. Acta Biomaterialia. 2009;5(9):3625-3639.

22. Mareci D, Chelariu R, Ciurescu G, Sutiman D, Gloriant T. Eletrochemical aspects of Ti-Ta alloys in HBSS. Materials and Corrosion. 2010;61(9):768-774.

23. Aziz-Kerrzo M, Conroy KG, Fenelon AM, Farrell ST, Breslin $\mathrm{CB}$. Electrochemical studies on the stability and corrosion resistance of titanium based implant materials. Biomaterials. 2001;22(12):1531-1539. 